\title{
Oral Health Behavior and Factors Influencing the Selection of Oral Hygiene Products among the Adolescent Tobacco Consumers in Jharkhand
}

\author{
Ajoy K Shahi ${ }^{1}$, Subhash Chandra ${ }^{2}$, Sandeep Kumar ${ }^{3}$, Swati Sharma ${ }^{4}$, Virendra K Prajapati ${ }^{5}$, Bishnupati Singh ${ }^{6}$
}

\begin{abstract}
Aim: To identify the oral health behavior and factors influencing the selection of oral hygiene products by the adolescent tobacco consumers in Ranchi district, Jharkhand. This study will also attempt to identify the factors related to the selection of toothbrushes for oral hygiene maintenance. Materials and methods: A total of 800 adolescent tobacco consumers were selected from Ranchi district. A self-administered questionnaire collected information on the oral health behavior and factors influencing the selection of oral cleansing aids. Logistic regression analysis was performed.

Results: Toothbrush (83.0\%) and toothpaste (78.0\%) were the most common oral cleansing aids. Media played an important role in the selection of toothbrushes and toothpaste. The dental visit (15.0\%) for preventive dental care was reported to be less. The individuals belonging to upper class $\left(\mathrm{OR}=2.8, p\right.$ value $\left.<0.001^{*}\right)$, of nontribal origin $\left(\mathrm{OR}=3.21, p\right.$ value $<0.001^{*}$, and residing in urban areas $\left(\mathrm{OR}=5.6, p\right.$ value $\left.<0.0001^{*}\right)$ were more likely to use a toothbrush.

Conclusion: The consumption of tobacco should be discouraged. Promotion of oral cleansing aids and interdental aids should be carried out using support from media.

Clinical significance: The oral health behavior of adolescents needs to be improved. The adolescents should be promoted to quit tobacco, and education and counseling should be provided to them for the oral health promotion. Regular dental check-up for preventive care should be encouraged.
\end{abstract}

Keywords: Adolescents, Interdental aids, Tobacco, Toothbrush, Toothpaste.

The Journal of Contemporary Dental Practice (2019): 10.5005/jp-journals-10024-2660

\section{INTRODUCTION}

Oral health is closely associated with health, and poor oral health can have a detrimental effect on general health. ${ }^{1}$ Oral health and general health are closely interrelated; there is a global burden of oral diseases among the most common noncommunicable diseases. ${ }^{2}$ Oral diseases can lead to infection, inflammation, and other serious impacts on overall health. ${ }^{3}$ According to the World Health Report, 2003, oral diseases are qualified as major public health problems due to their high incidence and prevalence in all regions of the world. ${ }^{2}$ Oral diseases such as dental caries, periodontal disease, tooth loss, oral mucosal lesions, oropharyngeal cancers, and dental trauma are considered as the major public health problems.

Tobacco consumption is very prevalent in the Indian population, and a number of studies conducted have shown that tobacco has a negative impact on oral health and health-related quality of life. ${ }^{4-6}$

Health behaviors are crucial indicators of oral health status. Effective and efficient oral hygiene practices are an essential tool for achieving good oral health. ${ }^{7,8}$ Toothbrushes and toothpaste are the most commonly used and effective method for plaque reduction and enamel remineralization as reported by a number of studies., ${ }^{9,10}$ Other oral hygiene aids include dental floss, wood stick, interspaced brush, and interproximal brush. ${ }^{11}$ A number of factors determine the selection of oral cleansing aids. Socioeconomic status, information from media (advertisements), and material properties such as taste, flavor, color, and appearance have been reported to influence the choice of an oral hygiene aids product. ${ }^{12}$

\begin{abstract}
${ }^{1,5}$ Department of Oral and Maxillofacial Surgery, Dental Institute, Rajendra Institute of Medical Sciences, Ranchi, Jharkhand, India

${ }^{2}$ Department of Orthodontics, Dental Institute, Rajendra Institute of Medical Sciences, Ranchi, Jharkhand, India

${ }^{3}$ Department of Public Health Dentistry, Dental Institute, Rajendra Institute of Medical Sciences, Ranchi, Jharkhand, India

${ }^{4}$ Department of Pedodontics, Dental Institute, Rajendra Institute of Medical Sciences, Ranchi, Jharkhand, India

${ }^{6}$ Department of Prosthodontics, Dental Institute, Rajendra Institute of Medical Sciences, Ranchi, Jharkhand, India
\end{abstract}

Corresponding Author: Subhash Chandra, Department of Orthodontics, Dental Institute, Rajendra Institute of Medical Sciences, Ranchi, Jharkhand, India, Phone: +91 9955393983, e-mail: drscportho@gmail.com

How to cite this article: Shahi AK, Chandra S, Kumar S, et al. Oral Health Behavior and Factors Influencing the Selection of Oral Hygiene Products among the Adolescent Tobacco Consumers in Jharkhand. J Contemp Dent Pract 2019;20(10):1200-1205.

Source of support: Nil

Conflict of interest: None

In India, tobacco consumption is very prevalent and it has a negative impact on oral health. The consumption of tobacco by adolescents increases the risks for premalignant and malignant lesions and simultaneously impairs oral health, making an individual more prone to periodontal diseases, halitosis, development of oral mucosal lesions, and others. ${ }^{13-15}$ Hence, a good oral health 
behavior of adolescents is an important factor that minimizes the harmful impact of tobacco consumption on oral structures. Very limited studies have been carried out to determine the oral health behavior and factors influencing the selection of oral cleansing products by tobacco consumers. Hence, this study was carried out with the aim to identify the oral health behavior and factors influencing the selection of oral hygiene products by the adolescent tobacco consumers in Ranchi district, Jharkhand. This study will also attempt to identify the factors related to the selection of toothbrushes as a means of oral cleansing aids. The study findings will enable policymakers to improve the oral health status of tobacco consumers particularly in early age (adolescents) and also focus on strategies to implement and promote the use of toothbrushes by the general population and high-risk communities.

\section{Materials and Methods}

\section{Study Design, Study Area, and Population}

This cross-sectional study was carried out in Ranchi district, Jharkhand, and included 800 adolescent tobacco consumers. It was carried out in the month of January 2018-February 2019 (13 months). For the above purpose, Ranchi district was divided into four zones. From each of these zones, two places were randomly selected for data collection. It included an equal number of rural and urban areas from each zone in order to maintain homogeneity for data collection.

\section{Selection of Sample, Sampling Technique, Inclusion and Exclusion Criteria}

The study populations were selected using a simple random technique from each of the identified locations of the four zones of Ranchi districts. The adolescents who gave the history of tobacco consumption for more than a year, willing to participate, and signed the informed consent were included in the study.

\section{Sample Size Calculation}

For the calculation of sample size, a pilot study was carried out on a sample of 20 individuals. These samples were selected from Dental Out-Patient Department of Dental Institute, RIMS. Based on the prevalence of dental caries, which is the most common oral disease affecting the oral cavity, the sample size was calculated using the formula recommended by the World Health Organization survey. ${ }^{16}$

$$
N=\frac{Z^{2} P(1-P)}{(0.05)^{2}} \times 100
$$

Using the above formula, with the estimated prevalence of dental caries to be $50 \%$, it was found that the minimum sample size required for the study was 384. A design effect correction of 2 is recommended for epidemiological studies. Hence, minimum sample size required would be $384 \times 2=768$. The study, however, included 800 adolescents in order to minimize the nonresponse rate.

\section{Ethical Approval, Informed Consent}

The Institutional Ethics Committee, RIMS, Ranchi, granted ethical approval. Verbal informed consent was sought from the study subjects.

\section{Pretesting of Questionnaire}

A questionnaire was drafted which consisted of four parts. The first part of the questionnaire collected information on the sociodemographic characteristics, the second part of the questionnaire collected information on the oral health behavior of the respondents, the third part of the questionnaire collected information on dental visits and adverse habits, and the fourth part consisted of a series of three questions which collected information on various factors influencing the choice of products by the respondents. A similar questionnaire to assess the factors influencing the selection of the oral hygiene products has been used previously in the study carried out by Sharda..$^{17}$ It was, however, modified based on the responses obtained in the pilot study. The final version of the questionnaire was supplied to the respondents after being tested for complete reliability and validity.

The assessment of socioeconomic status was based on the modified Kuppuswamy scale. ${ }^{18}$ Based on the income, education, and occupation which were self-reported by the respondents, it was divided into upper, middle, and lower class.

The questionnaire was fabricated in the English language. It was then translated into the Hindi language which is the common language used by the population residing in Jharkhand. The validity of the questionnaire was checked by a back-translation method involving blind retranslation into the English language. It was verified by experts in both the languages. The reliability of the questionnaire was assessed using Cronbach's alpha, and it showed that the questionnaire had high internal reliability (Cronbach's alpha $=0.92$ ). The validity of the questionnaire was checked by a back-translation method.

\section{Data Collection}

The self-administered questionnaire was distributed to the randomly selected respondents by a single trained investigator. The respondents were not permitted to confer with each other. Any doubt during the filling of the questionnaire was clarified by the investigator himself. All the filled proforma were collected by the investigator after 15-20 minutes and sent for data analysis.

A health talk was provided to the tobacco consumers focusing on various harmful effects of tobacco and the methods of quitting them. The adolescents were referred to the Dental Institute, RIMS, Ranchi, for further management.

\section{Statistical Analysis}

Data were analyzed using SPSS v 20. Frequency distribution analysis was performed. Logistic regression analysis was performed to identify the factors affecting the selection of the toothbrushes by the study population. $p$ value $<0.05$ was considered statistically significant.

\section{Results}

There was almost a nearly equal (50\%) representation of males and females, adolescents of tribal and nontribal origin, and residents of rural and urban areas in the study population. Nearly one-third of the adolescents (32.5\%) belonged to the upper class, $34.5 \%$ belonged to the middle class, and 33\% belonged to the lower class. Thus, it showed that there was an equal representation from all sections of the society (Table 1).

A majority of the study population used the toothbrush (83.0\%) and toothpaste $(78.0 \%)$ for oral hygiene maintenance. Very few of the adolescents (22.0\%) reported to brush with frequency twice or more daily. More than half of the adolescents (65.0\%) brushed their teeth using a combination of vertical and horizontal scrub technique. Mouthwash (8.0\%) was the most commonly used oral 
hygiene aid by the study population. The use of other oral hygiene aid like a toothpick (3.5\%) and dental floss (2.5\%) reported by the adolescents was negligible (Table 2 ).

Smokeless form of tobacco consumption (61.5\%) was most prevalent among adolescents with a majority of them (80.0\%) reporting the habit to be present for more than 5 years of duration. Only $15 \%$ of the adolescents reported to have visited a dentist for preventive care (Table 3).

The media (35.5\%) were identified as the most common factor influencing the selection of the toothbrushes by the adolescents.

Table 1: Sociodemographic characteristics of the study population

\begin{tabular}{lll}
\hline Variables & Categories & $n(\%)$ \\
\hline Age & $<15$ years & $386(48.3)$ \\
Gender & $\geq 15$ years & $414(51.7)$ \\
& Male & $430(53.8)$ \\
Socioeconomic status & Female & $370(46.2)$ \\
& Upper class & $260(32.5)$ \\
Origin & Middle class & $276(34.5)$ \\
& Lower class & $264(33.0)$ \\
Residence & Tribal & $396(49.5)$ \\
& Nontribal & $404(50.5)$ \\
& Urban & $400(50.0)$ \\
& Rural & $400(50.0)$ \\
\hline
\end{tabular}

Table 2: Oral health behavior of the study population

\begin{tabular}{lll}
\hline Variables & Categories & $n(\%)$ \\
\hline Oral hygiene aid used & Toothbrush & $664(83.0)$ \\
& Finger/other methods & $136(17.0)$ \\
Materials used & Toothpaste & $624(78.0)$ \\
& Toothpowder & $144(18.0)$ \\
& Others & $32(4.0)$ \\
Frequency of brushing & Once daily & $624(78.0)$ \\
& Twice or more & $176(22.0)$ \\
Brushing technique & Vertical scrub & $76(9.5)$ \\
& Horizontal scrub & $84(10.5)$ \\
& Combination of these & $520(65.0)$ \\
& techniques & $120(15.0)$ \\
Any other oral hygiene & Circular method & $64(8.0)$ \\
aid used & Mouthwash & \\
& & $28(3.5)$ \\
& Toothpick & $20(2.5)$ \\
& Dental floss & $688(86.0)$ \\
\hline
\end{tabular}

Table 3: Dental visit and adverse habits present in the study population

\begin{tabular}{lll}
\hline Variables & Categories & $n(\%)$ \\
\hline Type of tobacco consumed & Smoke form & $184(23.0)$ \\
& Smokeless form & $492(61.5)$ \\
& Combination of both & $124(15.5)$ \\
Duration of tobacco con- & $<5$ years & $640(80.0)$ \\
sumed & & \\
& $\geq 5$ years & $160(20.0)$ \\
Dental visit & Yes & $120(15.0$ \\
& No & $680(85.0)$ \\
\hline
\end{tabular}

The cost of the toothbrush (26.8\%) followed by the brand name of the toothbrushes (18.0\%) were other factors influencing the selection of toothbrushes. Dentists (6.0\%), peers (2.4\%), and parental guidance (3.0\%) had less influence on the selection of toothbrushes by adolescents.

The media (40.0\%) followed by the parental guidance (38.0\%) had nearly equal influence on the selection of toothpaste by the adolescents. The role of dentists (1.5\%), peers (1.5\%), and parental guidance $(2.0 \%)$ were negligible.

The parental guidance (50.0\%) was the most common factor followed by the advice from the dentists $(26.7 \%)$ in the selection of other oral hygiene aids other than toothbrushes. The role of media (5.4\%) was negligible (Table 4).

The results of bivariate analysis showed that of the various factors tested, socioeconomic status ( $p$ value $<0.001^{*}$ ), the origin of the study population ( $p$ value $<0.001^{*}$ ), and the place of residence ( $p$ value $<0.0001^{*}$ ) were found to be significantly associated with the use of toothbrushes by the study subjects.

These factors that were found to be significant were then entered into the logistic regression model with the use of toothbrush as the dependent variable. It was found that individuals who belonged to the upper class (OR $=2.8, p$ value $<0.001^{*}$ ) were significantly more likely to use toothbrushes than lowerclass communities. The individuals of nontribal origin ( $O R=3.21$, $p$ value $<0.001^{*}$ ) were more likely to use toothbrush compared to the tribal origin. It was found that the use of toothbrushes was significantly higher by the urban population $(\mathrm{OR}=5.6, p$ value $<$ $0.0001^{*}$ ) compared to the rural population. Age and gender did not influence the use of toothbrushes by the Indian adolescent population (Table 5).

Table 4: Factors affecting the selection of oral cleansing aids by the study population

\begin{tabular}{lll}
\hline Variables & Categories & $n /$ total (\%) \\
\hline Factors influencing & Brand name & $120(18.0)$ \\
selection of toothbrush & Advised by dentist & $40(6.0)$ \\
& Appearance & $54(8.13)$ \\
& Cost & $178(26.8)$ \\
& Advice of peers & $16(2.4)$ \\
& Parental guidance & $20(3.0)$ \\
Factors influencing & Media & $236(35.5)$ \\
choice of toothpaste/ & Brand name & $15(2.0)$ \\
toothpowder & Parental guidance & $292(38.0)$ \\
& Advice of peers & $12(1.5)$ \\
& Advised by dentist & $12(1.5)$ \\
& Cost & $23(3.0)$ \\
& Color & $38(5.0)$ \\
& Medicated/nonmedicated & $54(7.0)$ \\
Factors influencing & Media & $307(40.0)$ \\
choice of other oral & Plavor & $15(2.0)$ \\
hygiene aids used other & Advice of peers & $56(50.0)$ \\
than toothbrush/ & Taste/flavor & $4(3.6)$ \\
toothpaste & Brand name & $4(3.6)$ \\
& Advise of dentist & $12(10.7)$ \\
& Information from media & $6(5.4)$ \\
\hline
\end{tabular}


Table 5: A bivariate analysis followed by logistic regression analysis to identify the factors associated with the use of toothbrushes (dependent variable) by the study population

\begin{tabular}{|c|c|c|c|c|c|}
\hline Variables & Categories & $\begin{array}{l}\text { Unadjusted odds ratio } \\
\text { (confidence interval) }\end{array}$ & $p$ value & $\begin{array}{l}\text { Adjusted odds ratio } \\
\text { (confidence interval) }\end{array}$ & $p$ value \\
\hline \multirow[t]{2}{*}{$\mathrm{Age}^{\#}$} & $<15$ years & $1.32(0.62-2.81)$ & 0.468 & & \\
\hline & $\geq 15$ years & & & & \\
\hline \multirow[t]{2}{*}{ Gender $^{\#}$} & Male & $1.05(0.56-2.62)$ & 0.388 & & \\
\hline & Female & & & & \\
\hline \multirow[t]{3}{*}{ Socioeconomic status } & Upper class & $2.8(1.63-2.88)$ & $<0.001^{*}$ & $2.9(1.66-2.82)$ & $<0.001^{*}$ \\
\hline & Middle class & $2.2(1.52-2.76)$ & & $2.4(1.60-2.80)$ & \\
\hline & Lower class & & & & \\
\hline \multirow[t]{2}{*}{ Origin } & Nontribal & $3.21(1.58-6.49)$ & $<0.001^{*}$ & $3.3(1.63-6.43)$ & $<0.001^{*}$ \\
\hline & Tribal & & & & \\
\hline \multirow[t]{2}{*}{ Residence } & Urban & $5.6(3.53-7.28)$ & $<0.0001^{*}$ & $6.3(3.81-7.44)$ & $<0.0001^{*}$ \\
\hline & Rural & & & & \\
\hline
\end{tabular}

${ }^{*} p$ value $<0.05$ : statistically significant difference

\# Not included in the logistic regression model as nonsignificant in bivariate analysis

\section{Discussion}

This study included a total of 800 adolescents. This age group was selected as adolescents are more likely to get addicted to tobacco consumption. The oral health behavior of the adolescents, if intervened at an early stage, can improve the oral health-related quality of life. The use of tobacco needs to be discouraged from the early stages. The incorporation of good oral habits using advanced cleansing aids would definitely play a vital role in improving the oral health status. In the present study, every attempt was made to have equal representation from all sections of the society (upper/middle/ lower class), an equal number of males and females was included, and the selection of a sample from rural and urban areas was carried out equally. Also, individuals in equal number having tribal and nontribal origin were included. This ensured a homogenous population, thereby improving the accuracy of results obtained in comparison to other similar studies. The other advantage of this study was that it was the first of its kind carried out in the population of Jharkhand, and tribal populations were included in this study. The study findings will throw light on the factors which influence the selection of oral cleansing aids in this mixed population, and it will enable policymakers to develop ways to improve the oral health status of the communities residing in the state.

A majority of the study population reported the use of toothbrush and toothpaste for oral hygiene maintenance. This is similar to the findings reported by Logaranjani et al. ${ }^{19}$ and Durrani et al., ${ }^{20}$ in which they found that the use of toothbrush and toothpaste for oral hygiene maintenance is very popular among the masses. The toothbrush is the principal instrument in general use for accomplishing plaque removal as a necessary part of disease control. ${ }^{21}$

However, unlike other studies, it was found that the use of toothpowder in conjunction with toothbrush or finger is very much prevalent. A number of studies have reported about the harmful effects of toothpowder on dental structures. Toothpowder leads to early wear of teeth making an individual more prone to abrasion and sensitivity. ${ }^{22}$ Dental health education needs to be provided and the use of toothpowder should be discouraged.

Majority of the adolescents brushed their teeth once daily. This is similar to the findings reported by Logaranjani et al. ${ }^{19}$ and
Goryawala et al. ${ }^{23}$ To maximize the oral health, the American Dental Association (ADA) and US Surgeon General recommend that individuals should brush twice and floss at least once a day and have regular prophylactic dental visits. ${ }^{24}$ The habit of brushing the teeth twice daily needs to be inculcated among the adolescents.

A majority of the study population were unaware of the correct brushing technique. A combination of the vertical and horizontal scrub technique was practiced by the adolescents. The incorrect brushing technique has a detrimental effect on oral structures leading to early wear of teeth. Improper tooth brushing technique can cause injury to the teeth as well as the supporting tooth structure. ${ }^{25}$ The modified bass technique ${ }^{26}$ is recommended for oral hygiene maintenance which needs to be demonstrated and promoted among the adolescents.

The use of other oral hygiene aids such as mouthwash, dental floss, and the toothpick was not very popular among the masses. The chemical plaque control is used as an adjunct to mechanical plaque control and helps to improve oral health. ${ }^{27}$ The use of interdental cleaning aids can remove plaque and accumulated food debris from areas inaccessible to toothbrushes, deliver chemotherapeutic agents, and reduce interdental gingivitis. ${ }^{28}$ However, in the present study, it was found that the use of interdental cleaning aids is not into much practice by the adolescents. The use of chemical plaque control and interdental cleansing aids needs to be promoted among the population.

More than half of the adolescents reported consuming a smokeless form of tobacco with a duration of more than 5 years. Tobacco contains a number of harmful chemicals which have adverse effects on the oral health. ${ }^{29,30}$ The long-term consumption of tobacco can lead to the development of premalignant and malignant lesions. ${ }^{29-32}$ The adolescents' age group is the most common age group at which this habit is initiated and continues lifelong. The consumption of tobacco is harmful. Hence, the habit of tobacco consumption needs to be intercepted at an early stage by counseling the patients and educating them about the harmful effects of tobacco consumption.

Media were the most important factor for the selection of toothbrushes by the adolescents. Similar findings were reported in studies carried out by Dilip ${ }^{33}$ and Sharda. ${ }^{17}$ In the present study, the cost of the toothbrush was another important factor that 
influenced the selection by the adolescent. This warrants the need for the development of efficient and cost-effective disposable toothbrushes which can easily be procured and used by the general population.

Media also served as an important factor for the selection of toothpaste by the adolescents which are similar to the findings reported by Singh. ${ }^{34}$ The parental guidance was the second most influential factor in the selection of toothpaste by the adolescents which is similar to the findings reported by Kote et al. ${ }^{35}$

A very few of the adolescents reported to have visited the dentist for a regular dental check-up. This type of phenomenon has been termed by Okunseri et al. ${ }^{36}$ as "healthy person nonvisitor effect" and also reported in a study carried out by Kumar et al. ${ }^{37}$ As per this concept, a person visits the dentist only when in pain or suffering from any oral disease which warrants urgent care. If the person does not have any oral emergency, he does not visit a dentist for a routine check-up. This may be one of the reasons due to which "advice of the dentist" had very little influence on the selection of toothbrush and toothpaste by the adolescents. Very few of the adolescents have visited the dentist and most of the individuals have attempted to manage the oral emergencies through home remedies. A regular dental check-up is an effective means to inhibit the disease at its incipient stage and thus prevent its further progression. Hence, adolescents should be encouraged for a routine dental check-up.

Parental guidance was the most important factor affecting the selection of other oral hygiene aids by adolescents. The role of media was found to have very little influence on adolescents. This may be attributed to the fact that the use of interdental cleaning aids such as dental floss, toothpicks, and others is seldom advertised. However, interdental cleansing aids play a significant role in improving oral health and should be promoted by the media and used by adolescents.

Socioeconomic status, origin, and place of residence were significantly associated with the use of the toothbrush. Age and gender did not seem to have a significant influence on the use of toothbrush by adolescents.

It was found that individuals belonging to the upper class were more likely to use a toothbrush as compared to the lower class. The cost of the toothbrush was an important factor reported by the individuals in the selection of toothbrushes for oral hygiene maintenance. It is obvious that toothbrushes being costly are afforded by higher class whereas the lower class still prefers to use a finger or other indigenous methods for oral hygiene maintenance.

Studies carried out by Al-lafi and $\mathrm{Ababneh}^{38}$ and Chawla ${ }^{39}$ have found that indigenous oral hygiene aids reduce the bacterial load considerably. The adolescents of tribal origin reported the use of indigenous oral hygiene aids for oral hygiene maintenance. The use of toothbrush was less prevalent by the tribal population which is similar to the findings of Singh et al. ${ }^{40}$ However, comparative studies have shown that chewing sticks are equal and sometimes even better than toothbrushes in removing plaque scores and improving gingival health. ${ }^{41,42}$

The use of toothbrush was more prevalent in urban areas compared to the rural population. Similar findings were reported in the study conducted by Kaur et al. ${ }^{43}$ This may be attributed to the fact that the adolescents residing in urban areas are educated and more aware of the oral hygiene maintenance than their rural counterparts. Also, individuals residing in urban areas have better socioeconomic status and can readily afford using a toothbrush for oral hygiene maintenance.
Socioeconomic status, the origin of an individual, and the place of residence had a significant impact on the use of toothbrush by the study population. The age and gender did not influence the use of toothbrush by the study population.

Although every effort has been taken to ensure to include a homogeneous population in order to improve the accuracy of the results, there were certain limitations of the study as well. Further longitudinal studies with representations from all age groups need to be carried out before the results can be generalized.

\section{Conclusion}

Toothbrush and toothpaste were the most common oral hygiene aid used by adolescents. Most of the adolescents were unaware of the correct brushing technique. The use of interdental cleansing aid like dental floss, the toothpick was not into much use by the adolescents. Most of the adolescents consumed a smokeless form of tobacco with a duration of more than 5 years. The dental visit reported was less. Media was the most important factor in the selection of toothbrush and toothpaste by adolescents. Parental guidance was the most important factor in the selection of other oral hygiene aid other than the toothbrush. It was found that adolescents belonging to upper class, of nontribal origin, and residing in urban areas were more likely to use toothbrushes.

\section{Clinical Significance}

The oral health behavior of adolescents needs to be improved. The adolescents should be promoted to quit tobacco, and education and counseling should be provided to them for the oral health promotion. Regular dental check-up for preventive care should be encouraged.

\section{References}

1. Mohan R, Venkatanarasu B, et al. Assessment of oral health status and dental treatment needs among 12- and 15-year-old schoolgoing children of fisherman community residing at East Coast Road, Chennai: A cross-sectional study. J Pharm Bioallied Sci 2019;11(2):S385-S392. DOI: 10.4103/JPBS.JPBS_42_19.

2. Godha S, Dasar PL, et al. Oral Health: A Window to your Overall Health. Int J Oral Health Med Res 2015;2(3):105-108.

3. Centre for diseases control (CDC). The Power of Prevention: Chronic disease. The public health challenge of the 21st century. National Center for Chronic Disease Prevention and Health Promotion 2009; $1-18$.

4. Zeng J, Tang Y, et al. Alcohol consumption, tobacco smoking, betel quid chewing and oral health associations with hypo pharyngeal cancer among men in Central South China: a case-control study. Cancer Manag Res 2019;11:6353-6364. DOI: 10.2147/CMAR. S203439.

5. Holliday RS, Campbell J, et al. Effect of nicotine on human gingival, periodontal ligament and oral epithelial cells. A systematic review of the literature. J Dent 2019;86:81-88. DOI: 10.1016/ j.jdent.2019.05.030.

6. Sen N, Bathija P, et al. Caries risk assessment using Cariogram model among smokeless tobacco users in India. Med Pharm Rep 2019;92(2):165-171. DOI: 10.15386/mpr-978.

7. Petersen PE, Kwan S. Evaluation of community-based oral health promotion and oral disease prevention - WHO recommendations for improved evidence in public health practice. Community Dent Health 2004;21(4):319-329.

8. Ainamo J, Parviainen K. Occurrence of plaque, gingivitis and caries as related to self reported frequency of toothbrushing in fluoride areas in Finland. Community Dent Oral Epidemiol 1979;7(3):142-146. DOI: 10.1111/j.1600-0528.1979.tb01202.x. 
9. Creeth JE, Kelly SA, et al. Effect of tooth brushing duration and dentifrice quantity on enamel remineralisation: An in situ randomized clinical trial. J Dent 2016;55:61-67. DOI: 10.1016/j.jdent.2016. 10.003 .

10. Schlueter N, Klimek J, et al. Relationship between plaque score and video-monitored brushing performance after repeated instruction-a controlled, randomized clinical trial. Clin Oral Investig 2013;17(2): 659-667. DOI: 10.1007/s00784-012-0744-y.

11. Umanah $A \cup$, Braimoh $O B$. Oral hygiene practices and factors influencing the choice of oral hygiene materials among undergraduate students at the University of Port Harcourt, Rivers State, Nigeria. J Dent Allied Sci 2017;6:3-7. DOI: 10.4103/2277-4696. 205440.

12. Paik DI, Moon HS, et al. Knowledge of and practices related to caries prevention among Koreans. J Public Health Dent 1994;54(4):205-210. DOI: 10.1111/j.1752-7325.1994.tb01216.x.

13. Christen AG. The impact of tobacco use and cessation on oral and dental diseases and conditions. Am J Med 1992;93(1A):S25-S31. DOI: 10.1016/0002-9343(92)90624-K.

14. Rad M, Kakoie S, et al. Effect of long-term smoking on whole-mouth salivary flow rate and oral health. J Dent Res Dent Clin Dent Prospects 2010;4(4):110-114. DOI: 10.5681/joddd.2010.028.

15. Sangkheaw S. Effects of Smoking on periodontal tissues and halitosis. J Dent Assoc Thai 2007;57(5):275-284.

16. World Health Organization. Oral Health Surveys, Basic Methods, World Health Organization. 4th ed., Geneva, Switzerland: AITBS Publishers; 1999.

17. Sharda A, Sharda J. Factors influencing choice of oral hygiene products used among the population of Udaipur, India. International Journal of Dental Clinics 2010;2(2):7-12.

18. Bairwa M, Rajput $M$, et al. Modified kuppuswamy's socioeconomic scale: social researcher should include updated income criteria, 2012. Indian J Community Med 2013;38(3):185-186. DOI: 10.4103/09700218.116358.

19. Logaranjani A, Mahendra J, et al. Influence of media in the choice of oral hygiene products used among the population of Maduravoyal, Chennai, India. J Clin Diagn Res 2015;9(10):ZC06-ZC08. DOI: 10.7860/ JCDR/2015/14552.6562.

20. Durrani F, Rahman F, et al. Oral hygiene practices and knowledge among residents of the trans-varuna region (India): A hospital-based study. 2018;16(2):154-159.

21. Hoover JN, Singer DL, et al. Clinical evaluation of a light energy conversion toothbrush. J Clin Periodontol 1992;19(6):434. DOI: 10.1111/j.1600-051X.1992.tb00674.x.

22. Kumar S, Acharya $S$, et al. Prevalence and risk factors for dental erosion among 11- to 14-year-old school children in South India. J Oral Sci 2013;55(4):329-336. DOI: 10.2334/josnusd.55.329.

23. Goryawala SN, Chavda PK, et al. A survey on oral hygiene methods practiced by patients attending dentistry department at a tertiary care Hospital from Central Gujarat. J Int Soc Prev Community Dent 2016;6(2):115-119. DOI: 10.4103/2231-0762.178750.

24. Jiang $H$, Petersen PE, et al. Self assessed dental health, ora health practices, and general health behaviors in Chinese urban adolescents. Acta Odontol Scand 2005;63(3):343-352. DOI: 10.1080/ 00016350500216982.

25. Joshi CP, Patil AG, et al. Comparative evaluation of cemental abrasion caused by soft and medium bristle hardness toothbrushes at three predetermined toothbrushing forces: An in vitro study. J Indian Soc Perodontal 2017;21(1):10-15. DOI: 10.4103/jisp.jisp_118_17.

26. Wilkins Esther M. Clinical practice of the Dental Hygienist, 3rd ed. Philadelphia: Lea and Febiger; 1999. pp. 277-355.

27. Poyato-Ferrera M, Segura-Egea JJ, et al. Comparison of modified Bass technique with normal toothbrushing practices for efficacy in supragingival plaque removal. Int J Dent Hyg 2003;1(2):110-114. DOI: 10.1034/j.1601-5037.2003.00018.x.

28. Jafer M, Patil $S$, et al. Chemical plaque control strategies in the prevention of biofilm-associated oral diseases. J Contemp Dent Pract 2016;17(4):337-343. DOI: 10.5005/jp-journals-10024-1851.

29. Bouwsma OJ, Yost KG, et al. Comparison of a chlorhexidine rinse and a wooden interdental cleaner in reducing interdental gingivitis. Am J Dent 1992;5(3):143-146.

30. Niaz K, Maqbool F, et al. Smokeless tobacco (paan and gutkha) consumption, prevalence, and contribution to oral cancer. Epidemiol Health 2017;39:e2017009. DOI: 10.4178/epih.e2017009.

31. Muthukrishnan A, Warnakulasuriya S. Oral health consequences of smokeless tobacco use. Indian J Med Res 2018;148(1):35-40. DOI: 10.4103/ijmr.IJMR_1793_17.

32. Gupta B, Bray F, et al. Associations between oral hygiene habits, diet, tobacco and alcohol and risk of oral cancer: A case-control study from India. Cancer Epidemiol 2017;51:7-14. DOI: 10.1016/ j.canep.2017.09.003.

33. Dilip CL. Health status, treatment requirements, knowledge and attitude towards oral health of police recruits in Karnataka. Journal of Indian Association of Public Health Dentistry 2005;5(5):20-34.

34. Singh S. Effectiveness of advertisement on toothpaste product:a case study in Jhajjar district. International Journal of Applied Research 2017;3(1):403-405.

35. Kote $\mathrm{S}$, Dadu M, et al. Knowledge, attitude and behavior for choosing oral hygiene aids among Students of Management Institutes, Ghaziabad, India. West Indian Med J 2013;62(8):758-763.

36. Okunseri C, Chattopadhyay A, et al. Pilot survey of oral health-related quality of life: a cross sectional study of adults in Benin City, EdoState, Nigeria. BMC Oral Health 2005;5:7. DOI: 10.1186/1472-6831-5-7.

37. Kumar S, Debnath N, et al. Prevalence and Risk Factors for Oral Potentially Malignant Disorders in Indian Population. Adv Prev Med 2015;2015:208519. DOI: 10.1155/2015/208519.

38. Al-lafi T, Ababneh $\mathrm{H}$. The effect of the extract of the Miswak used in Jordon and the Middle East on oral bacteria. Int Dent Journal 1995;45(3):218-222.

39. Chawla HS. A new natural source for topical fluoride. J Indian Dent Assoc 1983;55(10):419-422.

40. Singh A, Bharathi MP, et al. Oral health status and practices of 5 and 12 year old Indian tribal children. J Clin Pediatr Dent 2011 Spring;35(3):325-330. DOI: 10.17796/jcpd.35.3.c8063171438k4362.

41. Malik AS, Shaukat MS, et al. Comparative Effectiveness of chewing stick and Toothbrush: A Randomized Clinical Trial. N Am J Med Sci 2014;6(7):333-337. DOI: 10.4103/1947-2714.136916.

42. Bhambal AB, Kothari SK, et al. Comparative effect of neem stick and toothbrush on plaque removal and gingival health - A clinical trial. J Adv Oral 2011;2(3):51-56. DOI: 10.1177/2229411220110322.

43. Kaur A, Gupta N, et al. An epidemiological study to determine the prevalence and risk assessment of gingivitis in 5-12 and 15-year-old children of rural and urban area of Panchkula (Haryana). Indian J Dent Res 2014;25(3):294-299. DOI: 10.4103/0970-9290.138310. 